\section{BRAZIULIAN JOURNAL}

OF MEDICAL AND BIOLOGICAL RESF ARCH

www.bjournal.com.br
ISSN 0100-879X

Volume 43 (03) 226-324 March 2010

BIOMEDICAL SCIENCES

AND

CLINICAL INVESTIGATION

Braz J Med Biol Res, March 2010, Volume 43(3) 279-284

Glucocorticoids, master modulators of the thymic catecholaminergic system?

I. Pilipović, D. Kosec, K. Radojević, M. Perišić, V. Pešić, Z. Stojić-Vukanić and G. Leposavić

The Brazilian Journal of Medical and Biological Research is partially financed by
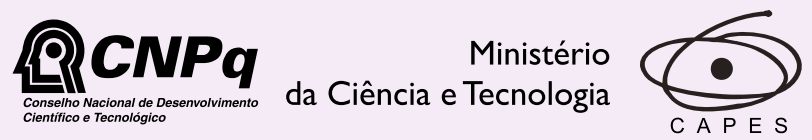

Ministério da Educação
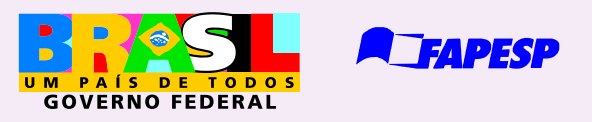

Institutional Sponsors 


\title{
Glucocorticoids, master modulators of the thymic catecholaminergic system?
}

\author{
I. Pilipović ${ }^{1}$, D. Kosec ${ }^{1}$, K. Radojević ${ }^{1}$, M. Perišić ${ }^{1}$, V. Pešić2 ${ }^{\text {, }}$ \\ Z. Stojić-Vukanić ${ }^{3}$ and G. Leposavić ${ }^{1,2}$ \\ ${ }^{1}$ Immunology Research Centre "Branislav Janković", Institute of Virology, \\ Vaccines and Sera "Torlak", Belgrade, Serbia \\ 2Department of Physiology, ${ }^{3}$ Department of Immunology and Microbiology, \\ Faculty of Pharmacy, University of Belgrade, Belgrade, Serbia
}

\begin{abstract}
There is evidence that the major mediators of stress, i.e., catecholamines and glucocorticoids, play an important role in modulating thymopoiesis and consequently immune responses. Furthermore, there are data suggesting that glucocorticoids influence catecholamine action. Therefore, to assess the putative relevance of glucocorticoid-catecholamine interplay in the modulation of thymopoiesis we analyzed thymocyte differentiation/maturation in non-adrenalectomized and andrenalectomized rats subjected to treatment with propranolol $\left(0.4 \mathrm{mg} \cdot 100 \mathrm{~g}\right.$ body weight ${ }^{-1}$. day $\left.{ }^{-1}\right)$ for 4 days. The effects of $\beta$-adrenoceptor blockade on thymopoiesis in non-adrenalectomized rats differed not only quantitatively but also qualitatively from those in adrenalectomized rats. In adrenalectomized rats, besides a more efficient thymopoiesis [judged by a more pronounced increase in the relative proportion of the most mature single-positive TCRa $\beta^{\text {high }}$ thymocytes as revealed by two-way ANOVA; for CD4 ${ }^{+} \mathrm{CD} 8^{-} \mathrm{F}(1,20)=$ 10.92, $\mathrm{P}<0.01$; for $\mathrm{CD} 4^{-} \mathrm{CD} 8^{+} \mathrm{F}(1,20)=7.47, \mathrm{P}<0.05$ ], a skewed thymocyte maturation towards the $\mathrm{CD}^{-} \mathrm{CD} 8^{+}$phenotype, and consequently a diminished $\mathrm{CD} 4^{+} \mathrm{CD} 8^{-} / \mathrm{CD} 4^{-} \mathrm{CD} 8^{+}$mature $\mathrm{TCRa} \beta^{\text {high }}$ thymocyte ratio $(3.41 \pm 0.21$ in non-adrenalectomized rats vs $2.90 \pm 0.31$ in adrenalectomized rats, $P<0.05$ ) were found. Therefore, we assumed that catecholaminergic modulation of thymopoiesis exhibits a substantial degree of glucocorticoid-dependent plasticity. Given that glucocorticoids, apart from catecholamine synthesis, influence adrenoceptor expression, we also hypothesized that the lack of adrenal glucocorticoids affected not only $\beta$-adrenoceptor- but also $\alpha$-adrenoceptor-mediated modulation of thymopoiesis.
\end{abstract}

Key words: Catecholamines; Glucocorticoids; $\beta$-adrenoceptors; Propranolol; Thymocyte apoptosis; Thymocyte proliferation; Thymocyte differentiation

\section{Introduction}

It is well known that stress causes profound involution of the thymus gland (1). Increased secretion of catecholamines (CAs) and glucocorticoids (GCs), the end-products of the sympatho-adrenal and hypothalamo-pituitary-adrenal (HPA) axes, respectively, is the major trademark of the prototypical stress response $(2,3)$.

Ample evidence from denervation and pharmacological studies (4-6) has implicated CAs in the fine-tuning of thymopoiesis (reviewed in Ref. 7). There is strong evidence that CAs exert thymus-dependent immunomodulatory effects via $\beta$-adrenoceptors ( $\beta$-ARs) (reviewed in Refs. 7,8). However, there are data indicating that some of the effects of CAs on the thymus may be mediated via a-ARs $(5,9)$.

It has been demonstrated that both thymic lymphoid and non-lymphoid cells express glucocorticoid receptors
(GRs) $(10,11)$. Moreover, GCs have been implicated in the modulation of thymocyte development (12).

The sympatho-adrenal and HPA axes often act in concert, with the signaling pathways of CAs and GCs being interwoven (2). Furthermore, GCs stimulate: i) CA biosynthesis and release (13), ii) $\beta$-AR gene expression and the receptor downstream intracellular signaling (14), and iii) $\alpha_{1}$ - and $\alpha_{2}$-AR gene expression $(15,16)$. On the other hand, noradrenaline affects GR expression in a receptordependent manner (17).

On the basis of the above considerations, we hypothesized that CA modulation of thymopoiesis depends at least in part on circulating GC levels. To test this hypothesis we analyzed thymocyte differentiation/maturation in the absence and in the presence of the main source of

Correspondence: G. Leposavić, Department of Physiology, Faculty of Pharmacy, University of Belgrade, 450 Vojvode Stepe, 11221 Belgrade, Serbia. Fax: +381-11-2467-465. E-mail: gordana.leposavic@pharmacy.bg.ac.rs

Received July 26, 2009. Accepted January 26, 2010. Available online February 15, 2010. Published March 12, 2010. 
endogenous GCs following a 4-day long $\beta$-AR blockade with propranolol.

\section{Material and Methods}

\section{Animals}

Adult male DarkAgouti rats bred at the Immunology Research Centre "Branislav Janković" in Belgrade were used. Animals were housed under standard laboratory conditions with free access to food pellets and tap water.

\section{Chemicals and immunoconjugates}

All monoclonal antibodies (mAbs): fluorescein-isothiocyanate (FITC)-conjugated anti-CD4 (clone W3/25), phycoerythrin (PE)-conjugated anti-CD8 (clone MRC OX-8) and peridinin chlorophyll protein (PerCP)-conjugated antiTCRaß (clone R73) were purchased from Serotec (UK). The appropriate IgG isotype-matched controls were obtained from BD Biosciences Pharmingen, USA.

\section{Experimental protocol}

Circulating glucocorticoids were removed by bilateral adrenalectomy. Non-adrenalectomized (non-Adx) and adrenalectomized $(\mathrm{Adx})$ rats were treated with propranolol hydrochloride $\left(0.4 \mathrm{mg} \cdot 100 \mathrm{~g}\right.$ body weight ${ }^{-1} \cdot$ day $^{-1}, \mathrm{sc}$; Sigma Aldrich Gmbh, Germany) or saline for 4 consecutive days.

Rats were bilaterally Adx via a single dorsal incision under sodium phenobarbitone anesthesia (Nembutal, 40 $\mathrm{mg} / \mathrm{kg}$, ip; Serva, Germany) and subjected to propranolol or saline treatment from day 4 post-adrenalectomy. All Adx animals were given $0.9 \%$ saline to drink. To avoid changes in corticosterone levels due to diurnal variation the rats were sacrificed between 9:00 and 10:00 am. All experimental procedures followed the principles of the European Community's Council Directive of November 24, 1986 (86/609/ EEC) and were approved by the Immunology Research Center "Branislav Janković" Institutional Committee for Animal Care and Use.

\section{Thymic cell suspensions}

The thymi were removed, dissected free of parathymic lymph nodes and adherent membranous tissue and weighed. Cell suspensions were prepared by grinding the thymic tissue between the frosted ends of microscope slides and passing the ensuing suspensions through a fine nylon mesh. The single-cell suspensions were washed in ice-cold PBS containing $2 \%$ fetal calf serum (Gibco, USA) and $0.09 \%$ sodium azide (Sigma Aldrich; PS medium) and counted using an improved Neubauer hemocytometer.

\section{Flow cytometry analysis}

Analysis of $C D 4 / C D 8 / T C R \alpha \beta$ expression. Aliquots of $1 \times 10^{6}$ thymocytes were incubated simultaneously with
FITC-conjugated anti-CD4, PE-conjugated anti-CD8 and PerCP-conjugated anti-TCRa $\beta$ mAbs for 30 min on ice in the dark. Thymocytes were then washed with PS medium, fixed in $0.5 \mathrm{~mL} 1 \%$ paraformaldehyde (Sigma Aldrich) in PBS and kept at $4^{\circ} \mathrm{C}$ until analysis. All samples were analyzed with a FACScan flow cytometer (Becton Dickinson Immunocytometry Systems, USA). Non-specific IgG isotype-matched controls were used for each fluorochrome type to define background staining, while dead cells and debris were excluded from analysis by selective anterior and right-angle scatter gating. Twenty thousand cells per sample were analyzed using the CellQuest Software (Becton Dickinson).

Cell cycle analysis. Briefly, $10^{6}-10^{7}$ thymocytes in 0.4 $\mathrm{mL}$ PBS were fixed by dropwise addition of $0.4 \mathrm{~mL}$ ice-cold absolute ethanol for $30 \mathrm{~min}$, on ice. The cells were then centrifuged at $700 \mathrm{~g}$ for $5 \mathrm{~min}$ and $0.5 \mathrm{~mL} 1 \mathrm{mg} / \mathrm{mL}$ RNAse I-A (Sigma Aldrich) in PBS was added to the pellet. The samples were incubated at $37^{\circ} \mathrm{C}$ for $20 \mathrm{~min}$. After incubation, $0.5 \mathrm{~mL} 40 \mu \mathrm{g} / \mathrm{mL}$ propidium iodide (Sigma Aldrich) in PBS was added, and the samples were incubated for the next $10 \mathrm{~min}$ at room temperature in the dark. Finally, the samples were passed through a fine nylon mesh and analyzed with a FACScan flow cytometer.

Analysis of apoptotic cells. The cell susceptibility to apoptotic signals was analyzed in freshly isolated thymocytes stained with merocyanine (MC) 540 (Sigma Aldrich) as described previously (6). Briefly, a $1 \mathrm{mg} / \mathrm{mL}$ stock solution of MC540 in twice-distilled water was filtered through a $0.22-\mathrm{nm}$ filter and $5 \mu \mathrm{L}$ MC540 solution was added to $10^{6}-10^{7}$ thymocytes before FACS analysis. Samples were analyzed with a FACScan flow cytometer.

\section{Statistical analysis}

Data are reported as means \pm SEM. Statistical significance of the differences in propranolol-induced thymic effects between non-Adx and Adx rats was determined by two-way ANOVA followed by the Bonferroni test for post hoc comparisons using the GraphPad Prism 5.0 software (GraphPad Software, Inc., USA). Differences were considered to be significant when $\mathrm{P}<0.05$.

\section{Results}

Differential effect of propranolol on thymus weight and thymocyte yield in non-Adx and Adx rats

A 4-day propranolol treatment produced differential effects on thymus weight [adrenalectomy $\mathrm{x}$ propranolol interaction, $F(1,20)=4.281, P<0.05$ ] and thymocyte yield [adrenalectomy $x$ propranolol interaction, $F(1,20)=4.279, P$ $<0.05$ ] in non-Adx and Adx rats. Blockade of $\beta$-ARs affected neither thymus weight nor thymocyte yield in non-Adx rats, while it $(P<0.05)$ reduced the values of these parameters in $\mathrm{Adx}$ rats compared to the corresponding saline-injected controls (Table 1). 


\section{Differential effect of propranolol on thymocyte proliferative index in non-Adx and Adx rats}

There was a significant [adrenalectomy $\mathrm{x}$ propranolol interaction, $F(1,20)=4.479, P<0.05$ ] difference in the effects of propranolol on the percentage of proliferating thymocytes (cells in the S/G2M phases of the cell cycle) in non-Adx and Adx rats. Namely, propranolol $(P<0.05)$ affected thymocyte proliferation in non-Adx rats, causing an increase in the percentage of proliferating cells, while it had no effect in Adx rats (Table 1).

\section{Propranolol affected thymocyte apoptosis in Adx and non-Adx rats}

Two-way ANOVA showed a significant effect of propranolol on thymocyte apoptosis, but no significant propranolol $x$ adrenalectomy interaction $[F(1,20)=3.486, P>0.05]$. Namely, irrespective of the presence of adrenal glands, propranolol $(P<0.01)$ increased the percentage of apoptotic thymocytes (Table 1).

\section{Differential effect of propranolol on the distribution of thymocyte subsets as determined by CD4/CD8/ TCR $\alpha \beta$ expression in Adx and non-Adx rats}

As previously shown (7), twelve thymocyte subsets at distinct developmental stages were distinguished by plotting CD4 vs CD8 within each thymocyte population as determined by TCRa $\beta$ surface density (TCRa $\beta^{\text {high }}$, TCR $\alpha \beta^{\text {low }}$ and TCR $\alpha \beta^{-}$).

$T C R \alpha \beta$ - thymocytes. Regarding the relative proportions of all TCR $\alpha \beta^{-}$thymocyte subsets, two-way ANOVA revealed a significant propranolol $x$ adrenalectomy interaction [for CD4-CD8, $F(1,20)=6.67, P<0.05$; for $C D 4^{+}{ }^{-}{ }^{-} 8^{+}, F(1,20)$ $=6.42, P<0.05$; for $C D 4^{+} C D 8-F(1,20)=35.73, P<0.01$; for $\left.C D 4^{-} C D 8^{+}, F(1,20)=47.01,0.01\right]$. Propranolol increased the percentage of $\mathrm{CD}^{-}{ }^{-} \mathrm{CD} 8^{-}$double-negative (DN) cells in both non-Adx and $A d x$ rats $(P<0.01)$, but this effect was more pronounced in $\mathrm{Adx}$ rats (Figure $1 \mathrm{Aa}, \mathrm{Ba}$ ). Following propranolol treatment, the relative proportions of $\mathrm{CD} 4^{+} \mathrm{CD} 8^{+}$ double-positive (DP) and CD4 ${ }^{+} \mathrm{CD} 8^{-}$single-positive (SP) cells were decreased $(P<0.01$ and $P<0.05$, respectively), but to a greater extent in non-Adx rats (Figure $1 \mathrm{Aa}, \mathrm{Ba}$ ). Propranolol had opposing effect on the relative proportion of $\mathrm{CD} 4^{-} \mathrm{CD} 8^{+} \mathrm{SP}$ cells in non-Adx and Adx rats. Compared with the corresponding saline-treated controls, the percentage of these cells was decreased $(P<0.01)$ and increased $(P<0.01)$ in non-Adx and Adx rats, respectively (Figure $1 \mathrm{Aa}, \mathrm{Ba})$.

$T C R a \beta^{l o w}$ thymocytes. Compared with non-Adx rats, in Adx rats propranolol differently $[F(1,20)=66.97, P>0.01]$ affected only the DP subset of TCRaßlow cells. Namely, although propranolol $(P<0.01)$ increased the percentage of DP cells in both non-Adx and Adx rats compared with their respective saline-injected controls, this effect was more pronounced in non-Adx rats (Figure $1 \mathrm{Ab}, \mathrm{Bb}$ ). Propranolol had no effect on the relative numbers of cells belonging to any of the other three subsets of TCRa $\beta^{\text {low }}$ thymocytes in either non-Adx or Adx animals (Figure $1 \mathrm{Ab}, \mathrm{Bb}$ ).

$T C R \alpha \beta^{\text {high }}$ thymocytes. Regarding the relative proportions of all thymocyte subsets, two-way ANOVA revealed a significant propranolol $x$ adrenalectomy interaction [for $\mathrm{DN}$, $F(1,20)=4.63, P<0.05$; for DP, $F(1,20)=30.76, P<0.01$; for $\mathrm{CD}^{+}{ }^{+} \mathrm{CD} 8^{-}, \mathrm{F}(1,20)=10.92, \mathrm{P}<0.01$; for $\mathrm{CD} 4^{-} \mathrm{CD} 8^{+}$, $F(1,20)=7.47, P<0.05]$. Propranolol $(P<0.01)$ reduced the percentage of $D P$ thymocytes in non-Adx rats, but was ineffective in this respect in $\mathrm{Adx}$ rats (Figure $1 \mathrm{Ac}, \mathrm{Bc}$ ). On the other hand, although propranolol increased the relative proportions of $\mathrm{CD}^{+}{ }^{+} \mathrm{CD} 8^{-}(\mathrm{P}<0.01)$ and $\mathrm{CD} 4{ }^{-} \mathrm{CD} 8^{+}$ $(P<0.05)$ SP cells in both non-Adx and Adx rats, this effect was more pronounced in $\mathrm{Adx}$ rats (Figure $1 \mathrm{Ac}, \mathrm{Bc}$ ). Furthermore, a reduced $(P<0.05) \mathrm{CD}^{+} / \mathrm{CD}^{-}$cell ratio in propranolol-treated Adx rats $(2.90 \pm 0.31)$ compared with propranolol-treated non-Adx rats $(3.41 \pm 0.21)$ suggested a particularly pronounced effect of propranolol on the size of the $\mathrm{CD} 4{ }^{-} \mathrm{CD} 8^{+} \mathrm{SP}$ cell subset in Adx rats. In addi-

Table 1. Differential effect of 4-day propranolol treatment on thymus weight, thymocyte yield and proliferative index in adrenalectomized ( $\mathrm{ddx}$ ) and non-Adx adult rats compared to the corresponding saline-treated controls.

\begin{tabular}{lccccc}
\hline & \multicolumn{2}{c}{ Non-Adx rats } & & \multicolumn{2}{c}{ Adx rats } \\
\cline { 2 - 3 } \cline { 5 - 6 } \cline { 5 - 6 } & Saline & Propranolol & & Saline & Propranolol \\
\hline Thymus weight $(\mathrm{g})$ & $0.18 \pm 0.006$ & $0.17 \pm 0.016$ & & $0.31 \pm 0.016$ & $0.25 \pm 0.006^{*}$ \\
Thymocyte yield $(\mathrm{x} \mathrm{107})$ & $19.89 \pm 1.03$ & $17.76 \pm 0.27$ & & $62.29 \pm 2.01$ & $57.66 \pm 0.95^{*}$ \\
Proliferative index $(\%)$ & $9.32 \pm 0.38$ & $13.48 \pm 0.47^{*}$ & & $16.34 \pm 0.21$ & $19.33 \pm 1.87$ \\
Apoptosis $(\%)$ & $8.75 \pm 0.51$ & $12.36 \pm 0.34^{*}$ & & $3.27 \pm 0.35$ & $4.98 \pm 0.35^{*}$ \\
\hline
\end{tabular}

Data are reported as means \pm SEM $(N=6)$. Proliferative index $=$ percent of cells in the S/G2M phases of the cell cycle. Apoptosis was measured with merocyanine 540 . ${ }^{*} \mathrm{P}<0.05$ compared to the corresponding saline-treated controls (two-way ANOVA followed by the Bonferroni test for post hoc comparisons). 

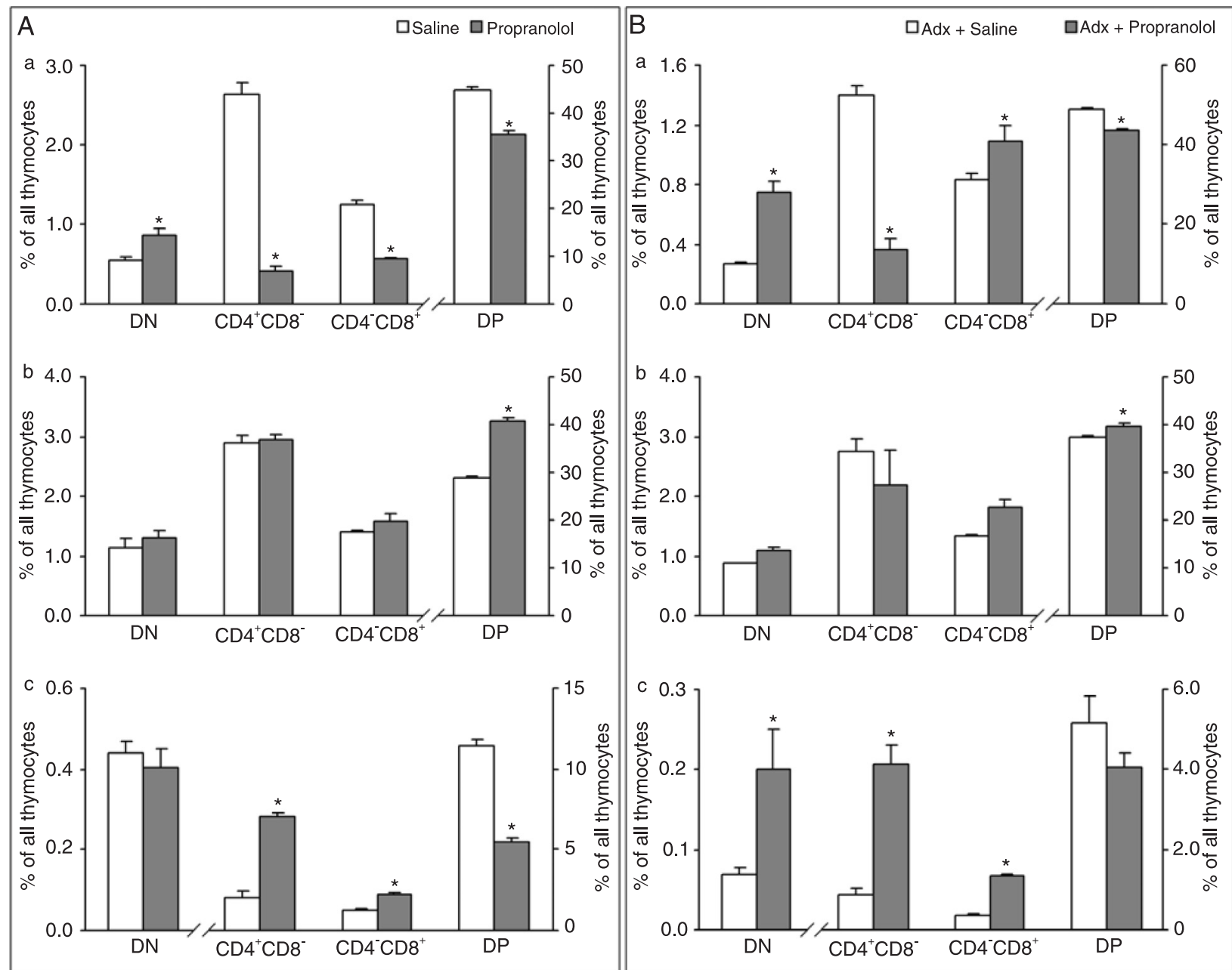

Figure 1. Differential effect of 4-day propranolol treatment on thymocyte subset distribution in non-adrenalectomized (non-Adx; panel A) and Adx adult male Dark Agouti rats (panel B). The histograms indicate the relative numbers of thymocyte subsets determined by CD4/CD8 expression with (a) undetectable (b) low and (c) high levels of TCRa $\beta$ in non-Adx and Adx rats treated with propranolol or saline. Data are reported as means \pm SEM $(N=6)$. $D N=C D 4{ }^{-C D} 8^{-}$, double-negative; $\mathrm{DP}=\mathrm{CD} 4^{+} \mathrm{CD} 8^{+}$, double-positive. ${ }^{*} \mathrm{P}<0.05$ compared to the corresponding saline-treated control (two-way ANOVA followed by the Bonferroni test for post hoc comparisons).

tion, in Adx rats, propranolol increased the percentage of DN cells compared to saline-injected rats, while in non-Adx rats the percentage of these cells was unaltered following propranolol treatment (Figure $1 \mathrm{Ac}, \mathrm{Bc})$.

\section{Discussion}

The results of the present study showed that a 4-day propranolol treatment has a differential effect on thymus weight and thymocyte yield in non-Adx and Adx rats. Propranolol (most likely due to a differential effect on thymocyte proliferation) reduced both thymic weight and cellularity in Adx, with no similar effect in non-Adx rats. Since the adrenaline level in adult rat thymus has been found to be below detection level (18), it may be assumed that the thy- mic changes in Adx rats mainly reflected a lack of adrenal GCs. This view is further supported by data showing that: i) noradrenergic nervous fibers represent the main source of CAs in the thymus $(7,8)$, and ii) surgical stress does not affect any of the thymopoiesis parameters analyzed (12). The ineffectiveness of propranolol in enhancing thymocyte proliferation in the absence of adrenal GCs may be explained by the fact that thymocyte proliferation was measured in an unfractionated thymocyte suspension. Namely, in Adx rats, an impaired $\alpha_{2}$-AR-mediated stimulatory effect of CA on proliferation of an $\alpha_{2}$-AR expressing thymocyte subset [due to reduced $\alpha_{2}-A R$ expression (16)], could mask the enhancing effects of the $\beta$-AR blockade on the proliferation of the thymocyte subset expressing $\beta$-ARs.

The analysis of thymocyte subset composition showed 
that propranolol treatment led to an overrepresentation of the least mature DN TCRaß- thymocytes in non-Adx rats, followed by the underrepresentation of their DP TCRa $\beta^{-}$ progeny. Furthermore, in these rats, propranolol treatment increased the relative proportion of DP TCRaßlow thymocytes (the cells entering positive selection) and the most mature SP TCR $\beta^{\text {high }}$ thymocytes, while it reduced that of intermediate DP TCR $\alpha \beta^{\text {high }}$ cells (the cells that had just undergone positive selection). Taken together, these findings suggest a decelerated transition from the DN TCR $\alpha \beta^{-}$to the DP TCR $\alpha \beta^{-}$developmental stage, followed by increased positive/reduced negative selection and accelerated post-selection differentiation/maturation. In view of the fact that: i) propranolol abrogates dose-dependent noradrenaline-induced destabilization of Thy- 1 mRNA in T-cell lines (19) and increases Thy-1 surface expression on thymocytes (7), and ii) Thy-1/- mice exhibit reduced positive/exaggerated negative selection and consequently a reduced proportion of mature SP cells (20), the alterations in thymocyte development in propranolol-treated non-Adx rats may be related at least in part to increased Thy-1 surface expression (data not shown).

In view of the fact that GCs increase CA synthesis and $\beta$-AR signaling $(14,15)$, a more efficient $\beta-A R$ blockade, and therefore more pronounced changes in thymopoiesis may be expected in thymi of Adx rats. Indeed, compared with non-Adx rats, in Adx rats propranolol caused a more pronounced increase in the proportion of the most immature DN TCRa $\beta^{-}$and the most mature (in particular $\mathrm{CD}^{-}{ }^{-} \mathrm{CD} 8^{+}$) SP TCR $\beta^{\text {high }}$ thymocytes. In addition, adrenalectomy partly (DP TCRaß ${ }^{-}$and DP TCRaß $\beta^{\text {low }}$ cells) or entirely (DP TCRa $\beta^{\text {high }}$ cells) abrogated the effects of $\beta$-AR blockade on the relative proportion of DP thymocytes. Generally, a more pronounced increase in the proportion of the least mature DN TCRaß ${ }^{-}$cells than in the proportion of the most

\section{References}

1. Eskandari F, Sternberg EM. Neural-immune interactions in health and disease. Ann N Y Acad Sci 2002; 966: 20-27.

2. Sapolsky RM, Romero LM, Munck AU. How do glucocorticoids influence stress responses? Integrating permissive, suppressive, stimulatory, and preparative actions. Endocr Rev 2000; 21: 55-89.

3. Padgett DA, Glaser R. How stress influences the immune response. Trends Immunol 2003; 24: 444-448.

4. Singh U. Effect of sympathectomy on the maturation of fetal thymocytes grown within the anterior eye chambers in mice. Adv Exp Med Biol 1985; 186: 349-356.

5. Plecas-Solarovic B, Hristic-Zivkovic I, Radojevic K, Kosec D, Leposavic G. Chronic alpha1-adrenoreceptor blockade produces age-dependent changes in rat thymus structure and thymocyte differentiation. Histol Histopathol 2005; 20 : 833-841.

6. Rauski A, Kosec D, Vidic-Dankovic B, Plecas-Solarovic B, Leposavic $\mathrm{G}$. Effects of beta-adrenoceptor blockade on the mature SP TCR $\alpha \beta^{\text {high }}$ cells following propranolol treatment in Adx compared with non-Adx rats may suggest a more pronounced increase in positive selection/decrease in negative selection. Furthermore, it may be speculated that the alteration in thymocyte selection (most likely reflecting a greater increase in Thy-1 thymocyte surface density due to a more efficient $\beta-A R$ blockade) in Adx rats not only compensated decelerated transition from the early DN TCR $\alpha \beta^{-}$to the DP TCR $\alpha \beta^{-}$developmental step but provided a substantially more pronounced increase in the relative proportion of the most mature SP thymocytes in these rats compared with non-Adx rats.

Moreover, given that: i) GCs enhance CA and $\alpha_{1}-A R$ expression $(14,16)$, and ii) the blockade of $\alpha_{1}$-ARs prevents the transition from the DN to DP thymocyte developmental steps and favors post-selection maturation towards mature $\mathrm{CD}^{+}{ }^{+} \mathrm{CD} 8^{-} \mathrm{SP}$ cells (6), it is reasonable to assume that a more pronounced increase in the proportion of DN TCR $\alpha \beta^{-}$cells and CD4-CD8 ${ }^{+}$SP TCRa $\beta^{\text {high }}$ cells following propranolol treatment in Adx rats compared with non-Adx rats reflected a substantially reduced $\alpha_{1}$-AR-mediated CA action.

In conclusion, the present study pointed to GC-dependent plasticity of CA-mediated fine-tuning of thymopoiesis, and indirectly suggested that GCs influence T-cell development, not only by a direct action on thymocytes and thymic non-lymphoid cells $(11,12)$, but also indirectly, affecting CA availability and/or AR sensitivity to CA signaling.

\section{Acknowledgments}

Research supported by grant \#145049 from the Ministry of Science and Technological Development, Republic of Serbia. phenotypic characteristics of thymocytes and peripheral blood lymphocytes. Int J Neurosci 2003; 113: 1653-1673.

7. Leposavic G, Pilipovic I, Radojevic K, Pesic V, Perisic M, Kosec D. Catecholamines as immunomodulators: a role for adrenoceptor-mediated mechanisms in fine tuning of T-cell development. Auton Neurosci 2008; 144: 1-12.

8. Elenkov IJ, Wilder RL, Chrousos GP, Vizi ES. The sympathetic nerve - an integrative interface between two supersystems: the brain and the immune system. Pharmacol Rev 2000; 52: 595-638.

9. Colic M, Cupic V, Pavicic L, Vucevic D, Varagic VM. Xylazine, an alpha 2-adrenergic agonist, modulates proliferation of rat thymocytes in vivo and in vitro. Methods Find Exp Clin Pharmacol 2000; 22: 557-562.

10. Plaut M. Lymphocyte hormone receptors. Annu Rev Immunol 1987; 5: 621-669.

11. Dardenne M, Itoh T, Homo-Delarche F. Presence of glucocorticoid receptors in cultured thymic epithelial cells. Cell 
Immunol 1986; 100: 112-118.

12. Stojic-Vukanic Z, Rauski A, Kosec D, Radojevic K, Pilipovic I, Leposavic G. Dysregulation of T-cell development in adrenal glucocorticoid-deprived rats. Exp Biol Med 2009; 234: 1067 1074.

13. Elhamdani A, Brown ME, Artalejo CR, Palfrey HC. Enhancement of the dense-core vesicle secretory cycle by glucocorticoid differentiation of PC12 cells: characteristics of rapid exocytosis and endocytosis. J Neurosci 2000; 20: 2495-2503.

14. Davies AO, Lefkowitz RJ. Regulation of beta-adrenergic receptors by steroid hormones. Annu Rev Physiol 1984; 46: 119-130.

15. Kavelaars A. Regulated expression of alpha-1 adrenergic receptors in the immune system. Brain Behav Immun 2002; 16: 799-807.

16. Hamamdzic D, Duzic E, Sherlock JD, Lanier SM. Regulation of alpha 2-adrenergic receptor expression and signaling in pancreatic beta-cells. Am J Physiol 1995; 269: E162-E171. 17. Lai M, McCormick JA, Chapman KE, Kelly PA, Seckl JR, Yau JL. Differential regulation of corticosteroid receptors by monoamine neurotransmitters and antidepressant drugs in primary hippocampal culture. Neuroscience 2003; 118: 975984.

18. Kendall MD, Atkinson BA, Munoz FJ, de la Riva C, Clarke $A G$, von Gaudecker B. The noradrenergic innervation of the rat thymus during pregnancy and in the post partum period. J Anat 1994; 185 (Part 3): 617-625.

19. Wajeman-Chao SA, Lancaster SA, Graf LH Jr, Chambers DA. Mechanism of catecholamine-mediated destabilization of messenger RNA encoding Thy-1 protein in T-lineage cells. J Immunol 1998; 161: 4825-4833.

20. Hueber AO, Bernard AM, Battari CL, Marguet D, Massol P, Foa $C$, et al. Thymocytes in Thy $1 \%$ mice show augmented TCR signaling and impaired differentiation. Curr Biol 1997; 7: 705-708. 